\title{
Bonding, aromaticity and reactivity patterns in some all-metal and non-metal clusters ${ }^{\dagger}$
}

\author{
S DULEY, S GIRI, A CHAKRABORTY and P K CHATTARAJ* \\ Department of Chemistry and Center for Theoretical Studies, Indian Institute of Technology, \\ Kharagpur 721302 \\ e-mail: pkc@chem.iitkgp.ernet.in
}

\begin{abstract}
Several sandwich-like metal clusters have been studied at the B3LYP/6-311+ G* level of theory. Bonding and reactivity have been analysed through various geometrical parameters and conceptual density functional theory based global reactivity descriptors. Aromaticity patterns have been understood in terms of the associated nucleus independent chemical shift values. Possibility of bond-stretch isomerism in some doped clusters is explored. Preferable sites for electrophilic and nucleophilic attacks have been identified using different local reactivity descriptors.
\end{abstract}

Keywords. Conceptual DFT; aromaticity; metal clusters; sandwich complexes.

\section{Introduction}

The concept of aromaticity ${ }^{1}$ in chemical systems has been introduced by Kekulé and since then this idea has been analysed under different contexts. ${ }^{2}$ The concept of aromaticity/antiaromaticity in chemical systems has become a popular classroom topic and the $(4 n+2) \pi$-electron rule for aromatic species is also well-known to the chemistry students. A lot of research has been carried out by both the theoreticians and the experimentalists by choosing several organic and inorganic systems like benzene and its derivatives, cyclic planar conjugated carbonsystems, borazines ${ }^{3}$ etc. Boldyrev et $a l^{4}$ in their breakthrough effort have added a new dimension to this concept. They have presented both theoretical and experimental evidences of aromaticity in an allmetal system $\mathrm{Al}_{4}^{2-}$. The $\mathrm{Al}_{4}^{2-}$ ring has been shown to be of perfect square planar geometry with two $\pi$-electrons delocalized through the entire skeleton of the all-metal framework. The HOMO is also of $\pi$-type in nature with a pair of such electrons. This has opened a new vista of further work on the topic of all-metal aromaticity and since then this seminal theme of all-metal aromaticity ${ }^{5}$ has been explored by several researchers. Scientists have also noticed that these all-metal multi-atomic aromatic systems are capable of forming strong bonds and/or closed

\footnotetext{
${ }^{\dagger}$ Dedicated to the memory of the late Professor S K Rangarajan *For correspondence
}

electronic structures. So a group of these atoms behave like a single superatom. These superatoms are undoubtedly novel synthones for the formation of a wide variety of all-metal sandwich-like clusters. ${ }^{6}$ Further advancements have shown that a wide variety of non-metallic $\mathrm{B}_{x}, \mathrm{~N}_{x}, \mathrm{P}_{x}$ superatoms ${ }^{7}$ can be used as building blocks for the formation of metalnon-metal clusters. In this study, we report the possible existence and reactivity of a variety of allmetal and metal-non-metal sandwich type as well as non-sandwiched flanked clusters. The stability, reactivity and aromaticity of all the cluster compounds are judged under the paradigm of conceptual density functional theory ${ }^{8}$ based global reactivity descriptors like electronegativity ${ }^{9}(\chi)$, hardness ${ }^{10}(\eta)$ and electrophilicity index ${ }^{11}(\omega)$ and local reactivity descriptors like atomic charges ${ }^{12}\left(Q_{k}\right)$ and the Fukui function $^{13}\left(f_{k}\right)$. The aromaticity measures of the complexes are analysed through calculation of the nucleus independent chemical shift (NICS) values of all the metallic and non-metallic rings by adopting the standard procedure as pescribed by Schleyer et $a l^{14}$. We also report a number of probable reactions that can occur upon replacement/substitution of the superatoms amongst themselves. The feasibility of these reactions is also evident from their respective reaction enthalpy $(\Delta H)$ and reaction electrophilicity $(\Delta \omega)$ values. Theoretical background of the present work is presented in Section 2 and section 3 provides the numerical details. Section 4 presents the results and discussion and finally, section 5 contains some concluding remarks. 


\section{Theoretical background}

For an N-electron system with total energy E, the electronegativity $^{9}(\chi)$ and hardness ${ }^{10}(\eta)$ can respectively be defined as the following first-order and second-order energy derivatives:

$$
\chi=-\mu=-\left(\frac{\partial E}{\partial N}\right)_{v(\vec{r})},
$$

and

$$
\eta=\frac{1}{2}\left(\frac{\partial^{2} E}{\partial N^{2}}\right)_{v(\vec{r})},
$$

where $\mu$ and $v(\vec{r})$ are chemical and external potentials respectively. Electrophilicity ${ }^{11}(\omega)$ is defined as:

$$
\omega=\frac{\mu^{2}}{2 \eta}=\frac{\chi^{2}}{2 \eta}
$$

For favourable reactions (say exothermic when entropy effects are neglected) $\omega$ often decreases. ${ }^{15}$

A finite difference approximation to the above derivatives provides

$$
\chi=\frac{I+A}{2}
$$

and

$$
\eta=\frac{I-A}{2}
$$

where the ionization potential $(I)$ and the electron affinity $(A)$ are expressed in terms of the energy of an N-electron system, $E(N)$, as

$$
I=E(N-1)-E(N),
$$

and

$$
A=E(N)-E(N+1) .
$$

One of the most important local reactivity descriptors is the Fukui function, ${ }^{13} f(\vec{r})$ which is given by

$$
f(\vec{r})=\left(\frac{\partial \rho(\vec{r})}{\partial N}\right)_{v(\vec{r})}=\left(\frac{\delta \mu}{\delta v(\vec{r})}\right)_{N},
$$

which means that it is a measure of the change in the electron density at a given point when electrons are added to or removed from the system at constant $v(\vec{r})$ or equivalently through a Maxwell relation it describes the change in the chemical potential when the external potential changes and the number of electrons remains conserved.

Condensation on individual atomic sites gives rise to ${ }^{16}$

$$
f_{k}^{+}=q_{k}(N+1)-q_{k}(N) \text { for nucleophilic attack }
$$

$$
\begin{aligned}
& f_{k}^{-}=q_{k}(N)-q_{k}(N-1) \text { for electrophilic attack (9b) } \\
& f_{k}^{o}=\left[q_{k}(N+1)-q_{k}(N-1)\right] / 2 \text { for radical attack, }(9 \mathrm{c})
\end{aligned}
$$

where $q_{k}$ refers to the electronic population of atom $k$ in a molecule.

Another local reactivity descriptor, philicity ${ }^{17}$ $\left(\omega_{k}^{\alpha}\right)$ is defined for analyzing the site selectivity as

$$
\omega_{k}^{\alpha}=\omega \cdot f_{k}^{\alpha}
$$

where $\alpha=+,-, 0$ denotes nucleophilic, electrophilic and radical attacks respectively.

The absolute magnetic shielding is represented as the nucleus independent chemical shift ${ }^{14}$ (NICS) which at the centre of a ring is designated as $\operatorname{NICS}(0)$.

\section{Numerical details}

All the generated molecular systems are optimized and their frequencies are calculated at the B3LYP/6$311+\mathrm{G}^{*}$ level of theory by using the Gaussian 03 program. ${ }^{18}$ The NIMAG values of all the structures are zero which confirmed their existence at the minima of the potential energy surface (PES). We choose the ferrocene moiety anion $(\mathrm{Cp}-\mathrm{Fe}-\mathrm{Cp})$ as the starting chemical system and have gradually substituted the two cyclopentadienyl anion $\left(\mathrm{Cp}^{-}\right)$rings with superatoms like $\mathrm{Al}_{4}^{2-}, \mathrm{B}_{3}^{-}, \mathrm{B}_{4}^{2-}, \mathrm{N}_{4}^{2-}$ and $\mathrm{P}_{4}^{2-}$. After obtaining $I$ and $A$ values using a $\triangle \mathrm{SCF}$ technique, the electronegativity and hardness are calculated using (4) and (5) respectively. Natural Population Analysis (NPA) scheme is used in the calculation of the atomic charges and the Fukui function. The global electrophilicity index $(\omega)$ is calculated from the explicit formula (3) involving chemical potential ${ }^{9}$ and hardness ${ }^{10}$ as proposed by Parr et al. ${ }^{11}$ In the last set we study a superatom ${ }^{19}\left[\mathrm{Mg}_{4} \mathrm{Be}_{4}\right]$ and its complexes $\left(\left[\mathrm{Mg}_{4} \mathrm{Be}_{4}-\mathrm{M}\right]\right.$; where $\mathrm{M}=\mathrm{Li}, \mathrm{Na}, \mathrm{K}, \mathrm{Be}, \mathrm{Mg}$, 


\section{Molecules}

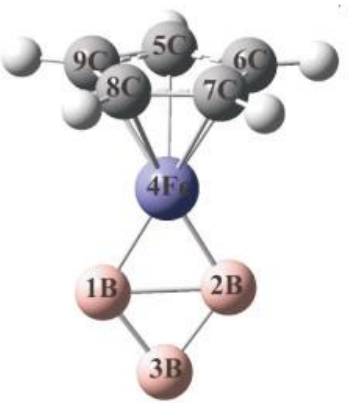

$\mathrm{Cp}-\mathrm{Fe}-\mathrm{B}_{3}$

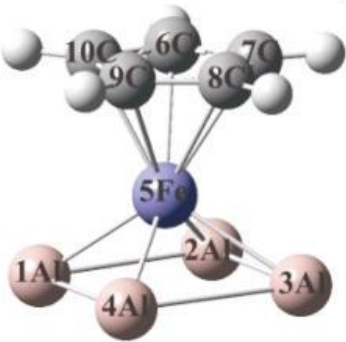

$\left[\mathrm{Cp}-\mathrm{Fe}-\mathrm{Al}_{4}\right]^{-}$

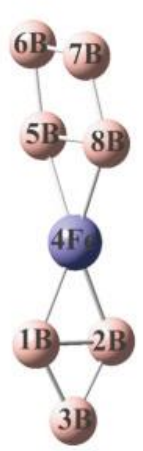

$\left[\mathrm{B}_{4}-\mathrm{Fe}-\mathrm{B}_{3}\right]^{-}$

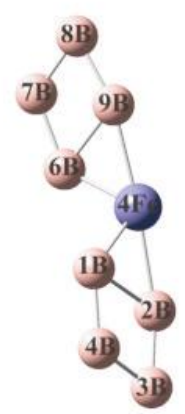

$\left[\mathrm{B}_{4}-\mathrm{Fe}-\mathrm{B}_{4}\right]^{2-}$

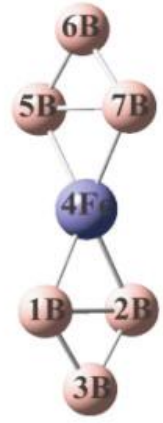

$\mathbf{B}_{3}-\mathrm{Fe}-\mathrm{B}_{3}$

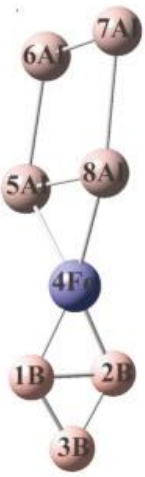

$\left[\mathrm{Al}_{4}-\mathrm{Fe}-\mathrm{B}_{3}\right]^{\top}$

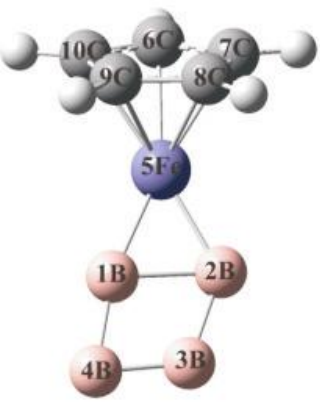

$\left[\mathrm{Cp}-\mathrm{Fe}-\mathrm{B}_{4}\right]^{-}$

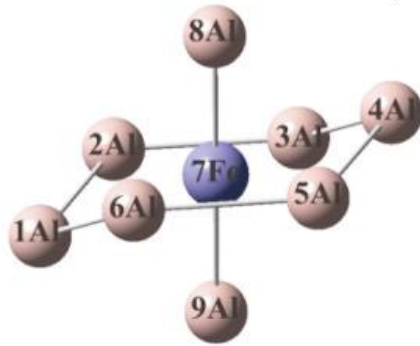

$\left[\mathrm{Al}_{4}-\mathrm{Fe}-\mathrm{Al}_{4}\right]^{2-}$

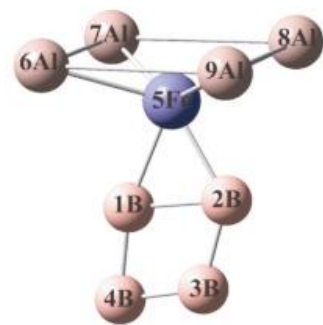

$\left[\mathrm{Al}_{4}-\mathrm{Fe}-\mathrm{B}_{4}\right]^{2-}$

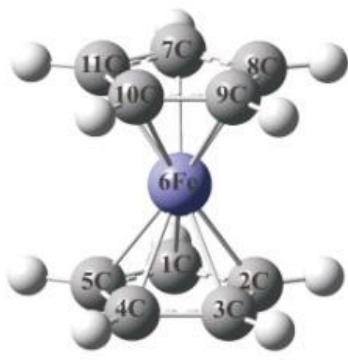

Cp-Fe-Cp

Figure 1. Optimized structures(B3LYP/6-311+G*) of the molecules involved in the scheme S1.

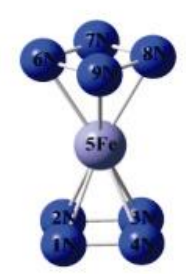

$\left[\mathrm{N}_{4}-\mathrm{Fe}-\mathrm{N}_{4}\right]^{2}$

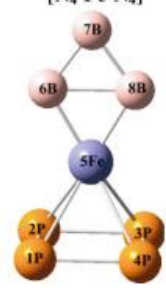

$\left[\mathrm{B}_{3}-\mathrm{Fe}-\mathrm{P}_{4}\right]^{-}$

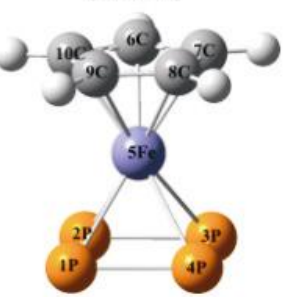

[Cp-Fe-P 4

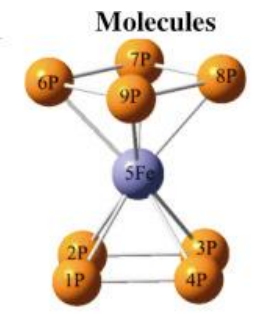

$\left[\mathrm{P}_{4}-\mathrm{Fe}-\mathrm{P}_{4}\right]^{2}$
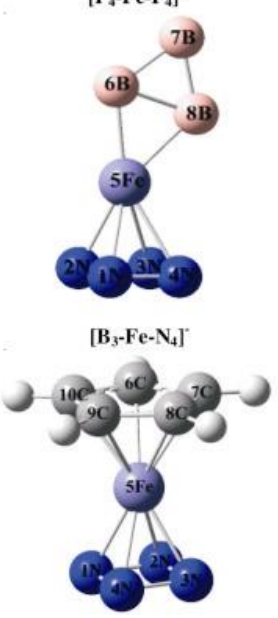

$\left[\mathrm{Cp}-\mathrm{Fe}-\mathrm{N}_{4}\right]$

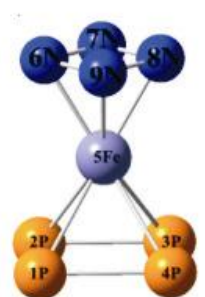

$\left[\mathrm{N}_{4}-\mathrm{Fe}-\mathrm{P}_{4}\right]^{2}$

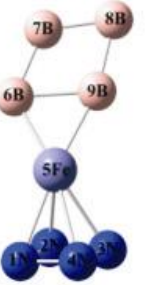

$\left[\mathrm{B}_{4}-\mathrm{Fe}-\mathrm{N}_{4}\right]^{2}$
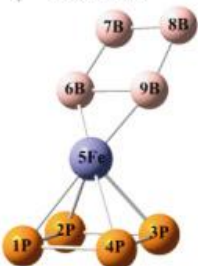

$\left[\mathrm{B}_{4}-\mathrm{Fe}-\mathrm{P}_{4}\right]^{2-}$
Figure 2. Optimized structures (B3LYP/6-311+G*) of the molecules involved in the scheme S2.
$\mathrm{Ca}, \mathrm{Sc}, \mathrm{Ti}, \mathrm{Cr}, \mathrm{Zn}, \mathrm{B}$ and C) with different alkali metal, alkaline earth metal, first row transition metal and non-metal atoms at B3LYP/6-311+ $\mathrm{G}^{*}$ level of theory in Gaussian 03 package. The frequency calculations are also carried out at the same level of theory. In all the cases we get zero imaginary frequency which implies that the complexes are of the minimum energy values in their ground states. Global reactivity descriptors like electronegativity $(\chi)$ and hardness $(\eta)$ are calculated from ionization potential (IP) and electron affinity (EA) which are obtained using $\triangle \mathrm{SCF}$ technique as described above. Electrophilicity index $(\omega)$ values of these complexes are obtained from (3). To get the atomic charges and other local reactivity descriptors like the Fukui func$\operatorname{tion}^{13}(\mathrm{FF})$ and the philicity ${ }^{17}\left(\omega_{k}^{\alpha}\right)$ we use natural population analysis scheme (NPA) for this set as well. We also calculate the nucleus independent chemical shift (NICS) values of mainly two rings $\left(\mathrm{Mg}_{4}\right.$ and $\left.\mathrm{Be}_{4}\right)$ of the complexes. Frontier molecular orbital pictures are obtained through GV 03 package.

\section{Results and discussion}

We segregate the possible reactions of our reported molecular systems into four reaction schemes. 


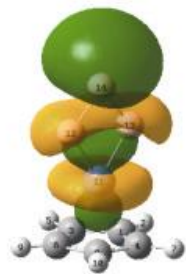

HOMO

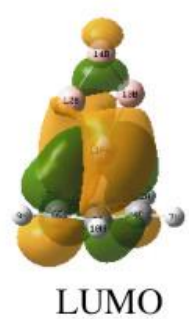

$\mathrm{Cp}-\mathrm{Fe}-\mathrm{B}_{3}$

\section{Molecules}

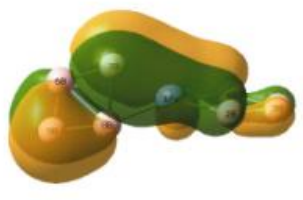

HOMO

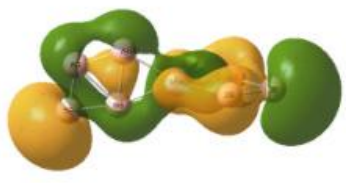

LUMO

$\left[\mathrm{B}_{3}-\mathrm{Fe}-\mathrm{B}_{4}\right]^{-}$

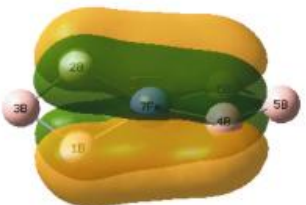

HOMO

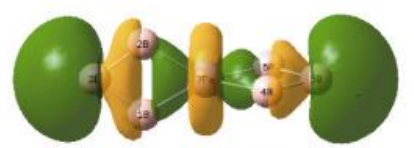

LUMO

$\mathrm{B}_{3}-\mathrm{Fe}-\mathrm{B}_{3}$

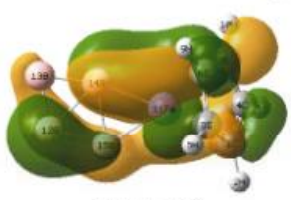

HOMO

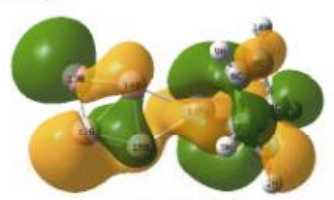

LUMO

$\left[\mathrm{Al}_{4}-\mathrm{Fe}-\mathrm{B}_{3}\right]^{-}$

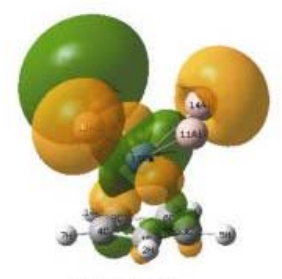

HOMO

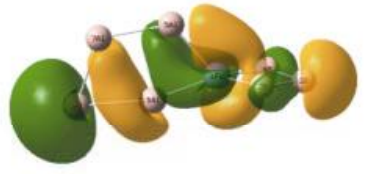

LUMO

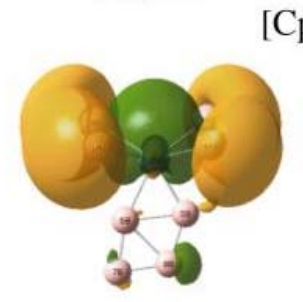

HOMO

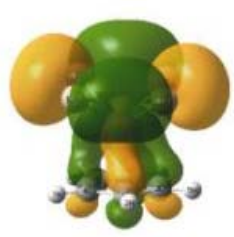

LUMO

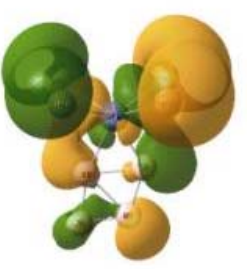

LUMO

$\left[\mathrm{Al}_{4}-\mathrm{Fe}-\mathrm{B}_{4}\right]^{2-}$

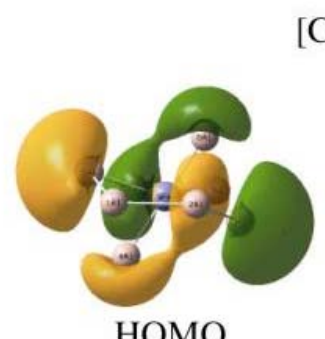

[Cp-Fe- $\left.\mathrm{B}_{4}\right]$

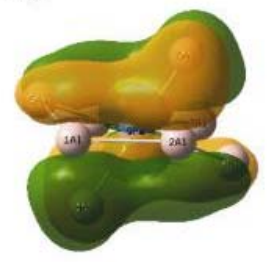

LUMO

$\left[\mathrm{Al}_{4}-\mathrm{Fe}-\mathrm{Al}_{4}\right]^{2-}$

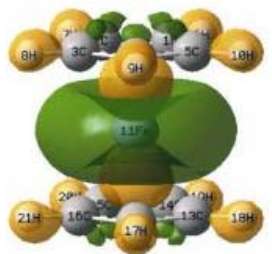

HOMO

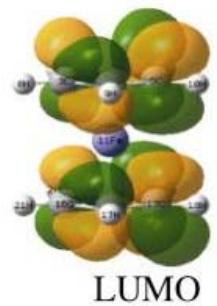

Cp-Fe-Cp

Figure 3. Some important frontier molecular orbital pictures of different molecules involved in the reactions (scheme S1).

Figures 1 and 2 present the optimized geometrical structures of the complexes of schemes S1 and S2 respectively (See supporting information for details). The total energy $(E$, a.u. $)$, electronegativity $(\chi, \mathrm{eV})$, hardness $(\eta, \mathrm{eV})$ and electrophilicity index $(\omega, \mathrm{eV})$ of all the molecular systems involved in the reaction schemes $\mathrm{S} 1$ and $\mathrm{S} 2$ are shown in tables $\mathrm{S} 1$ and $\mathrm{S} 2$ respectively. The molecular point groups (PG) and the NICS $(0)$ values of the chemical systems as well as that of the superatoms involved in schemes $\mathrm{S} 1$ and $\mathrm{S} 2$ are respectively shown in tables $\mathrm{S} 3$ and $\mathrm{S} 4$. The atomic charges $\left(Q_{k}\right)$ and the Fukui functions $f_{k}^{+}$ and $f_{k}^{-}$(NPA values) for nucleophilic and electrophilic attacks respectively, for the different systems 
Molecules

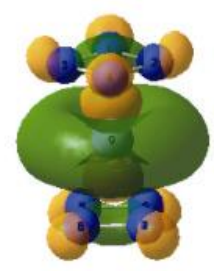

HOMO

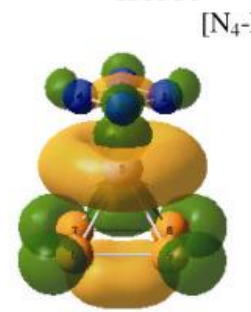

HOMO

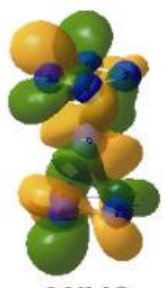

LUMO

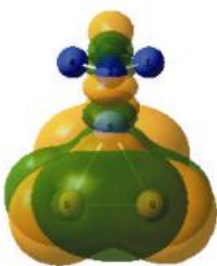

LUMO

$\left[\mathrm{N}_{4}-\mathrm{Fe}-\mathrm{P}_{4}\right]^{2-}$

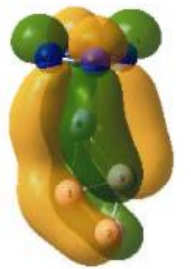

HOMO

$\left[\mathrm{B}_{3}-\mathrm{Fe}-\mathrm{N}_{4}\right]$

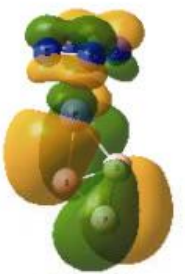

LUMO

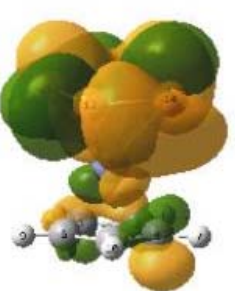

LUMO

HOMO

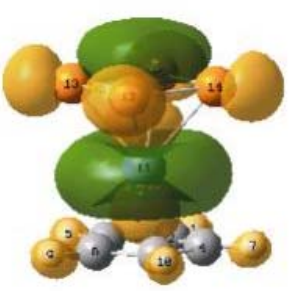

$\left[\mathrm{Cp}-\mathrm{Fe}-\mathrm{P}_{4}\right]$
Molecules

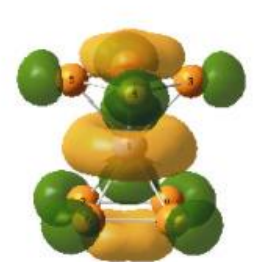

HOMO

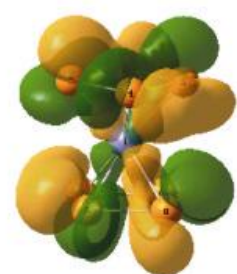

LUMO

$\left[\mathrm{P}_{4}-\mathrm{Fe}-\mathrm{P}_{4}\right]^{2-}$

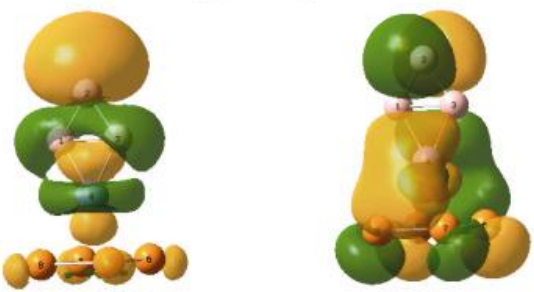

LUMO

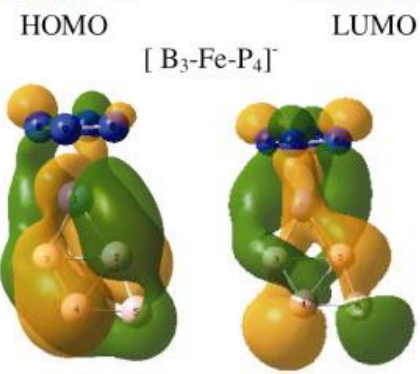

HOMO

$\left[\mathrm{B}_{4}-\mathrm{Fe}-\mathrm{N}_{4}\right]^{2-}$

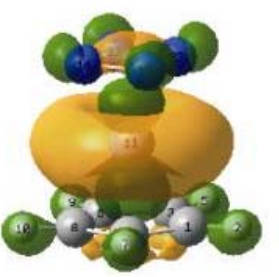

HOMO
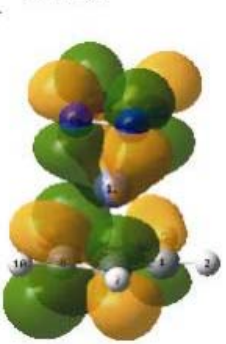

LUMO $\left[\mathrm{Cp}-\mathrm{Fe}-\mathrm{N}_{4}\right]^{-}$

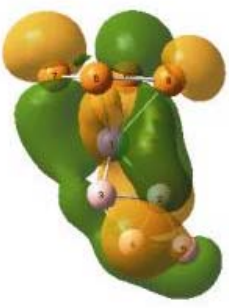

LUMO

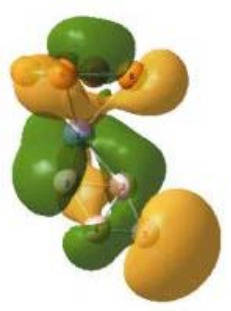

HOMO $\left[\mathrm{B}_{4}-\mathrm{Fe}-\mathrm{P}_{4}\right]^{2-}$

Figure 4. Some important frontier molecular orbital pictures of different molecules involved in the reactions (scheme S2).

involved are shown in tables S5 and S6 for the schemes S1 and S2 respectively. All the possible substitution and. replacement. reactions. involved in schemes S1 and S2 and their corresponding reaction enthalpies ( $\Delta H$ in $\mathrm{Kcal} /$ mole) and reaction electrophilicity values $(\Delta \omega$ in $\mathrm{eV})$ ) are provided in tables $\mathrm{S} 7$ and S8 respectively. Tables $\mathrm{S} 1$ and $\mathrm{S} 2$ highlight that the aromatic rings remain intact in most of the 

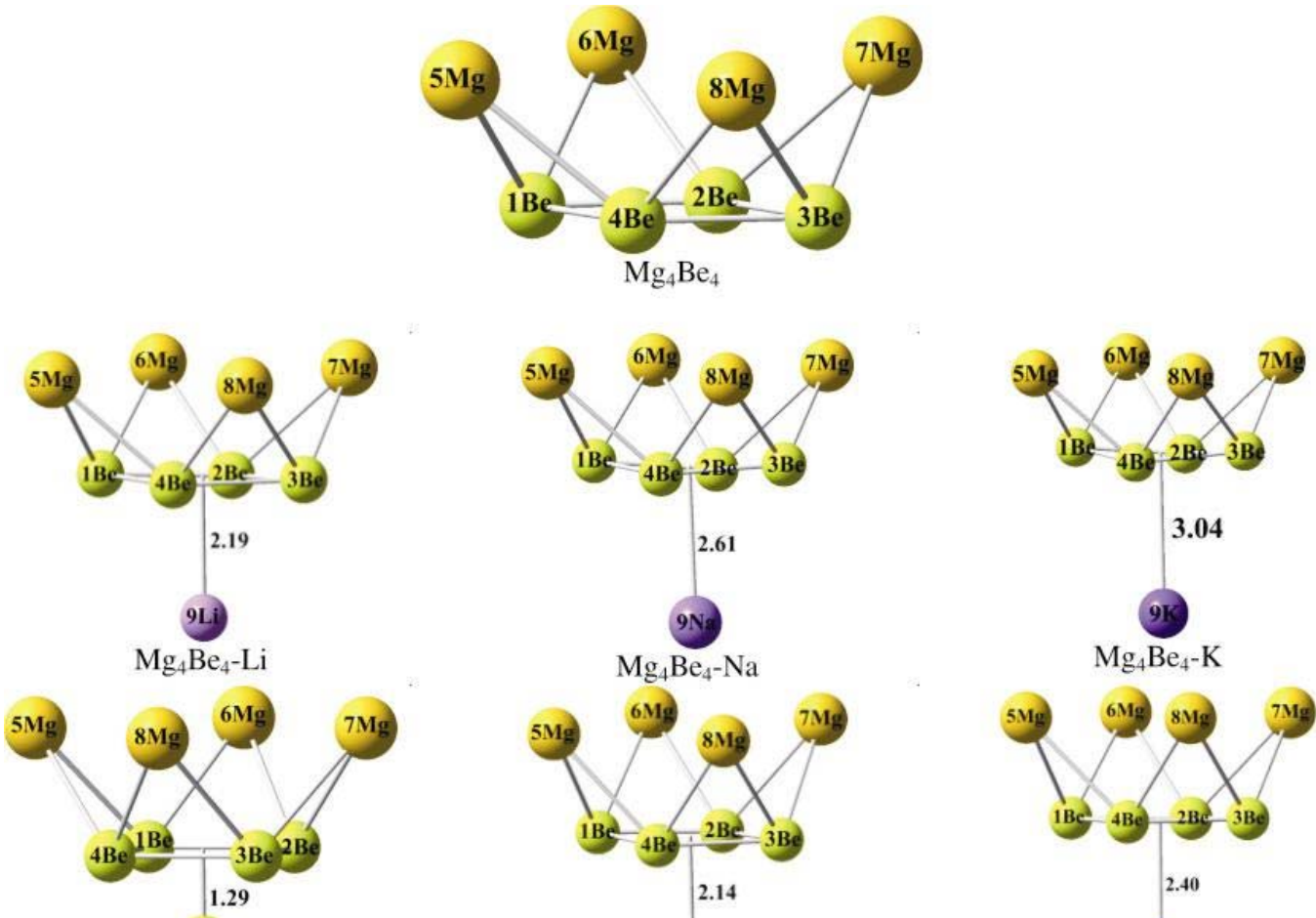

$9 \mathrm{Be}$

$\mathrm{Mg}_{4} \mathrm{Be}_{4}-\mathrm{Be}$
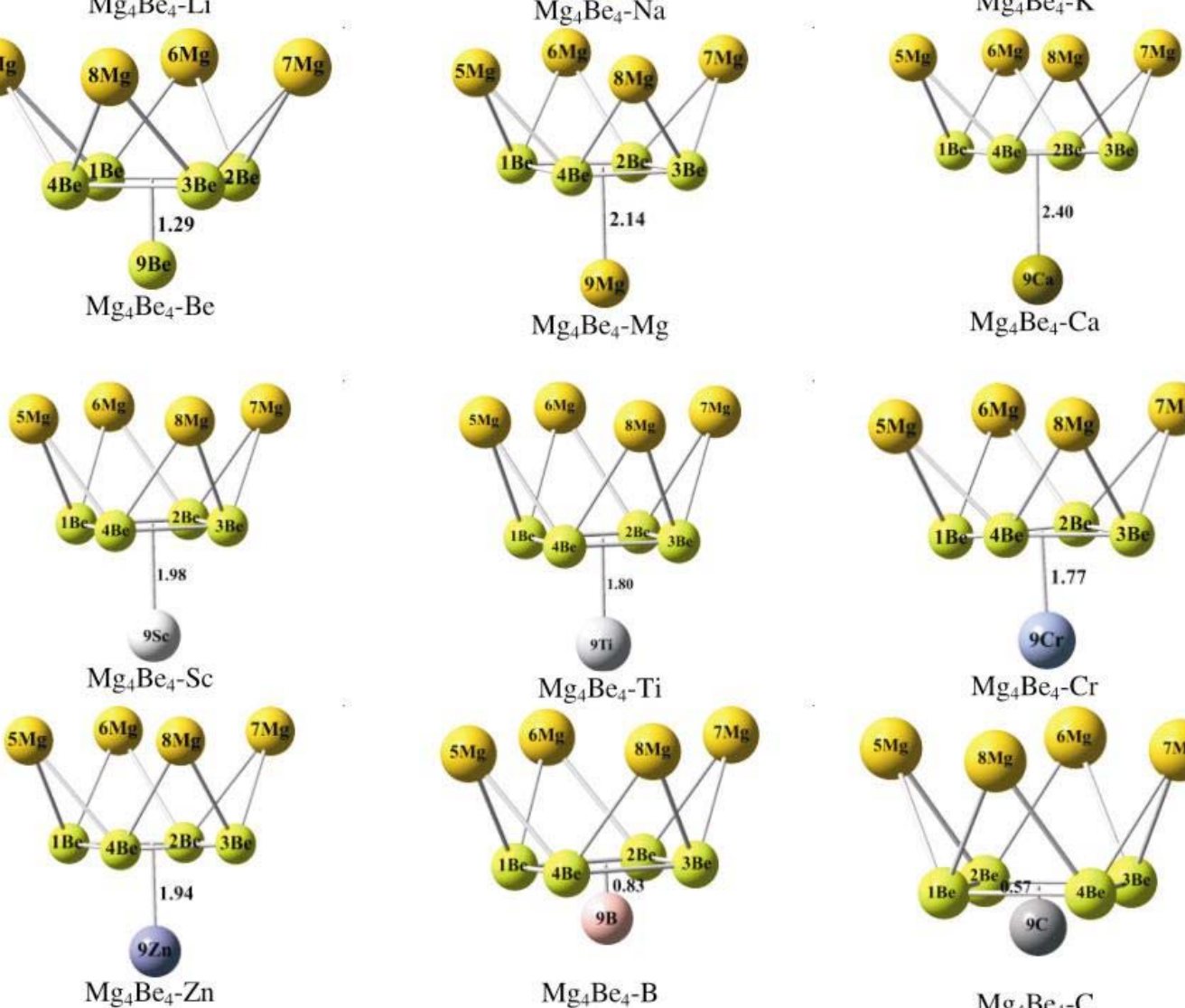

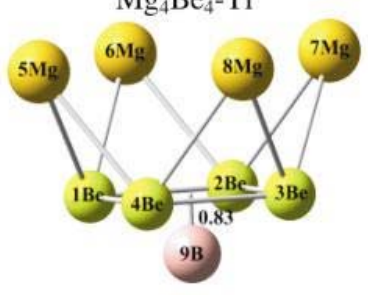

$\mathrm{Mg}_{4} \mathrm{Be}_{4}-\mathrm{B}$

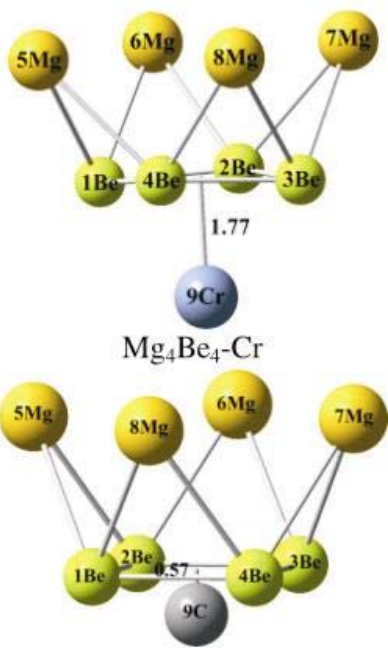

$\mathrm{Mg}_{4} \mathrm{Be}_{4}-\mathrm{C}$

Figure 5. Optimized structures (B3LYP/6-311+ G*) of the molecules involved in the scheme S3.

sandwich complexes which in turn may be straight, slipped, eclipsed or staggered. Although $\eta$ and $\omega$ values are positive in all cases (tables $\mathrm{S} 1$ and $\mathrm{S} 2) \chi$ is negative in some cases reflecting their disliking in accepting further electrons. From table $\mathrm{S} 3$ it becomes apparent that the superatoms involved in the reactions of scheme $\mathrm{S} 1$ almost retain their aromaticities even in the complexed form except for $\left[\mathrm{Al}_{4}\right]^{2-}$ in $\left[\mathrm{Al}_{4}-\mathrm{Fe}-\mathrm{B}_{4}\right]^{2-}$ and $\left[\mathrm{Al}_{4}-\mathrm{Fe}-\mathrm{Al}_{4}\right]^{2-}$ as well as $\left[\mathrm{B}_{4}\right]^{2-}$ and $\left[\mathrm{B}_{3}\right]^{-}$in $\left[\mathrm{B}_{3}-\mathrm{Fe}-\mathrm{B}_{4}\right]^{-}$. A more or less analogous mixed trends in the NICS $(0)$ values for the superatoms involved in reaction scheme $\mathrm{S} 2$ becomes relevant from table S4. While the NICS $(0)$ values for the $\mathrm{N}_{4}^{2-}$ and $\mathrm{P}_{4}^{2-}$ moieties in the free uncombined state reveal their antiaromatic nature, the same superatoms turn out to be aromatic in the complexed 


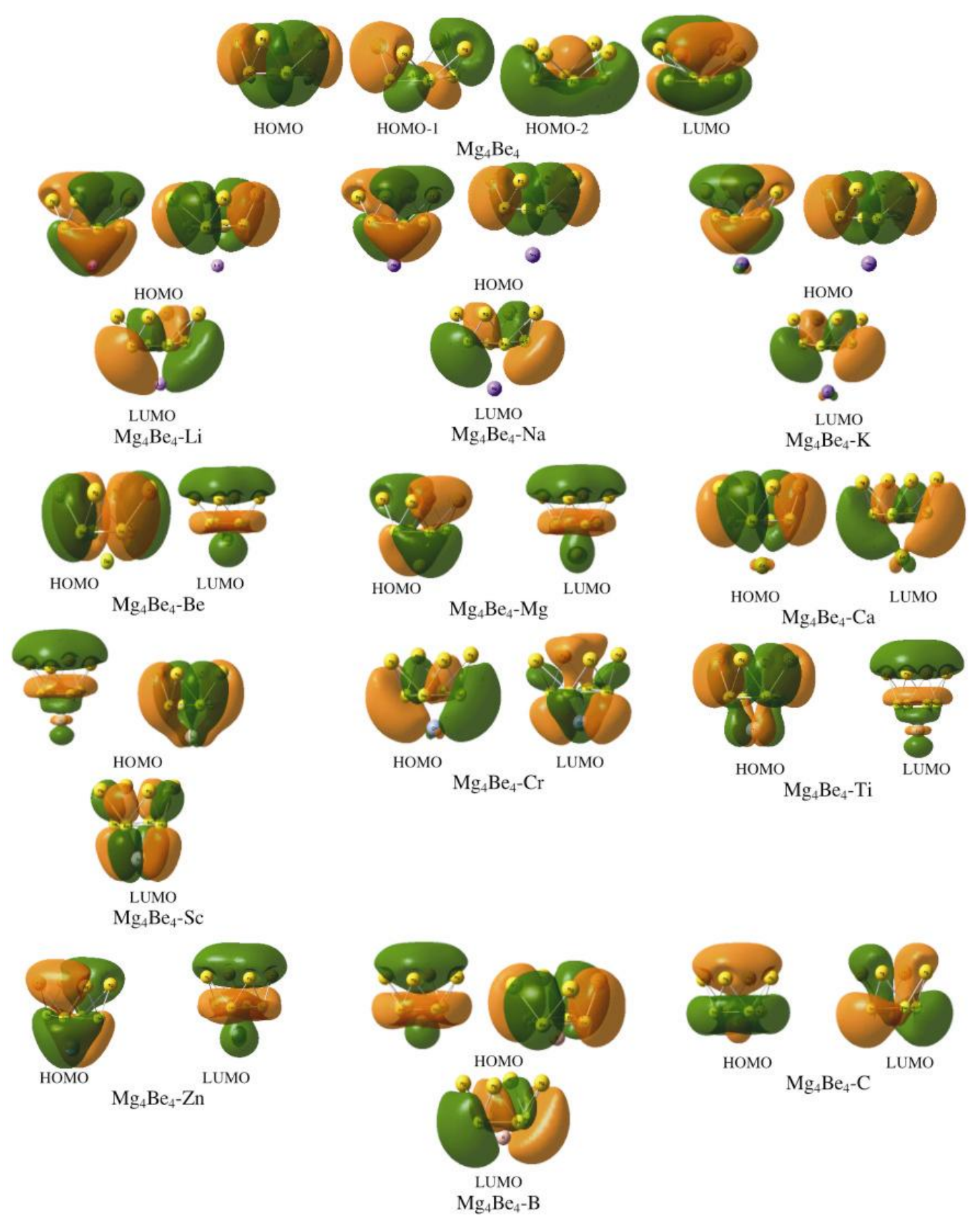

Figure 6. Some important frontier molecular orbital pictures of different metal clusters (scheme S3).

form. Thus a variation in the aromaticity trends for the different moieties can well be observed in course of the reactions. The atomic charges $Q_{k}$ (NPA) and the Fukui function values in tables S5 and S6 for schemes $\mathrm{S} 1$ and $\mathrm{S} 2$ respectively portray the change in reactivity pattern of the $\mathrm{Fe}$-center in the presence or absence of the cyclopentadienyl $\left(\mathrm{Cp}^{-}\right)$ring. In $[\mathrm{Cp}-\mathrm{Fe}-\mathrm{Cp}]$ the metal center acquired a positive charge and hence would be an ideal site to be targeted by an anion or a hard nucleophile. But a mixed trend is observed where the metal centers form complexes with the superatoms and $\mathrm{Cp}^{-}$. For all the complexes, $\mathrm{C}$ atoms in the $\mathrm{Cp}^{-}$ring are negatively charged and hence favourable for electrophilic attack. But for all the atom centers in the other moieties a mixed trend is observed. From tables S7 and S8 it is evident that all the substitution/replacement reactions are exothermic in nature. The reaction electrophilicity values $(\Delta \omega)$ for almost all of the reactions (one exception out of 35 cases) in both the proposed 

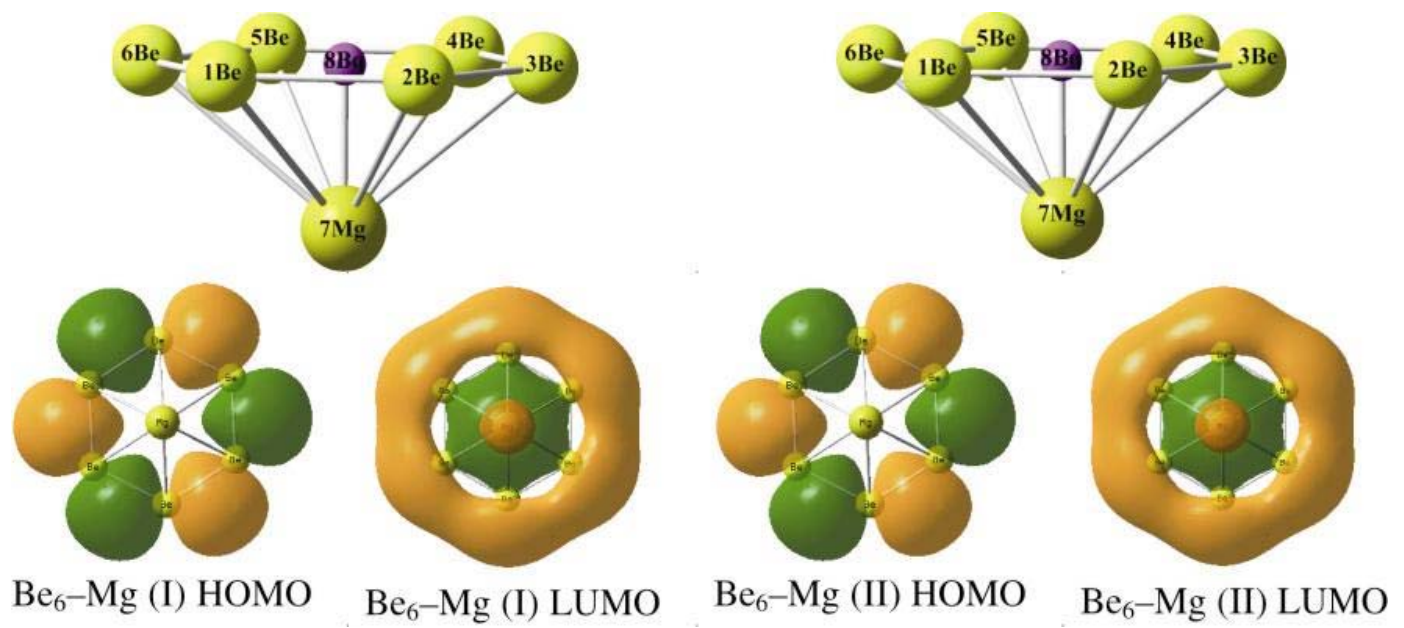

Figure 7. Optimized structures (B3LYP/6-311+G*) and some important frontier molecular orbital pictures of $\mathrm{Be}_{6}-\mathrm{Mg}$ isomers (scheme $\left.\mathrm{S} 4\right)$.

schemes are negative thereby affording some theoretical justification to their spontaneity as dictated by the minimum electrophilicity principle. ${ }^{15}$ Figures 3 and 4 illustrate the significant frontier molecular orbitals of the metal sandwich complexes. For the complexes of $\mathrm{Cp}^{-}, \mathrm{N}_{4}^{2-}$ and $\mathrm{P}_{4}^{2-}$ rings with $\mathrm{Fe}$ as central atom have similar molecular orbitals. The HOMO of ferrocene is essentially the $3 d_{z 2}$ orbital of Fe with hardly any overlap with the $\pi-\mathrm{MO}$ of $\mathrm{Cp}^{-}$. In other complexes $\sigma$ and $\pi$ aromaticities are observed owing to delocalization. The symmetry and planarity of $\mathrm{N}_{4}^{2-}$ and $\mathrm{P}_{4}^{2-}$ ring are preserved even after complexation with more overlap with the $3 d_{z 2}$ orbital in Fe than in the case of ferrocene. ${ }^{20}$ The square planar symmetry is marginally lost in the cases of unsymmetrical sandwich complexes although same amount of delocalization still persists. However, no such distinct delocalization is observed in the $\mathrm{HOMO}$ of $\left[\mathrm{Al}_{4}-\mathrm{Fe}-\mathrm{Al}_{4}\right]^{2-}$ complex as $\mathrm{Al}_{4}^{2-}$ ring loses its planarity upon complexation. For most of the unsymmetrical sandwich complexes with $\mathrm{Al}_{4}^{2-}$ unit in one end the ring, however, remains intact. Figure 5 presents the optimized geometries of some important crown like clusters ${ }^{19}$ of scheme S3 (see supporting information details). We start with the planar $\mathrm{Mg}_{4}$ and $\mathrm{Be}_{4}$ units with $\mathrm{D}_{4 \mathrm{~h}}$ symmetry. It is found that $\mathrm{Mg}_{4}$ and $\mathrm{Be}_{4}$ rings are planar in almost all the complexes except in $\left[\mathrm{Mg}_{4} \mathrm{Be}_{4}-\mathrm{Na}\right],\left[\mathrm{Mg}_{4} \mathrm{Be}_{4}-\mathrm{K}\right]$, $\left[\mathrm{Mg}_{4} \mathrm{Be}_{4}-\mathrm{Cr}\right]$ and $\left[\mathrm{Mg}_{4} \mathrm{Be}_{4}-\mathrm{Zn}\right]$. The bond distance between the center of $\mathrm{Be}_{4}$ ring and the reacting atom of the complexes increases when we move from $\mathrm{Li}$ to $\mathrm{K}$ and $\mathrm{Be}$ to $\mathrm{Ca}$. But this is reverse for the complexes containing first row transition metals like Sc,
Ti, Cr except Zn and non-metals B and C. Tables S9 and S10 present the energy, electronegativity, hardness and electrophilicity values of the reacting atom and the complexes respectively. Nucleus independent chemical shift (NICS (0)) values of the complexes are provided in table $\mathrm{S} 11$. In all the cases but for the $\mathrm{Mg}_{4}$ units in $\left[\mathrm{Mg}_{4} \mathrm{Be}_{4}-\mathrm{Mg}\right]$ and $\left[\mathrm{Mg}_{4} \mathrm{Be}_{4}-\mathrm{Zn}\right]$ the NICS $(0)$ value is negative suggesting that all the complexes are aromatic in nature. Some important frontier molecular orbital pictures are shown in figure 6. From HOMO pictures (doubly degenerate in some case) it is evident that the complexes of $\mathrm{Li}$, $\mathrm{Na}, \mathrm{K}$ and $\mathrm{Zn}$ exhibit similar trends where mainly $\sigma$ delocalization is observed over the triangular $\mathrm{Be}-$ $\mathrm{Mg}-\mathrm{Be}$ unit. On the other hand in the cases of the complexes of $\mathrm{Sc}, \mathrm{B}$, and $\mathrm{C}$ discernible delocalization is observed over the four-membered $\mathrm{Mg}_{4}$ and $\mathrm{Be}_{4}$ units. Table $\mathrm{S} 12$ presents the reaction enthalpy $(\Delta H)$ and the reaction electrophilicity $(\Delta \omega)$ of the formation reactions of different metal clusters. In all the cases the reaction enthalpy and reaction electrophilicity are negative which indicates that the reactions are exothermic in nature and the minimum electrophilicity principle ${ }^{15}$ seems to be operative. The atomic charges (NPA), Fukui functions (for both electrophilic and nucleophilic attacks) and the associated philicity values are given in table S13. For all the cases the $\mathrm{Mg}_{4}$ ring atoms are favourable for nucleophilic attack and the $\mathrm{Be}_{4}$ ring atoms are better sites for electrophilic attack for most of the cases except in the complexes of $\left[\mathrm{Mg}_{4} \mathrm{Be}_{4}-\mathrm{Ti}\right]$, $\left[\mathrm{Mg}_{4} \mathrm{Be}_{4}-\mathrm{B}\right]$ and $\left[\mathrm{Mg}_{4} \mathrm{Be}_{4}-\mathrm{C}\right]$ and two alternative $\mathrm{Be}$ atoms in $\mathrm{Be}_{4}$ ring of $\left[\mathrm{Mg}_{4} \mathrm{Be}_{4}-\mathrm{Cr}\right]$. 


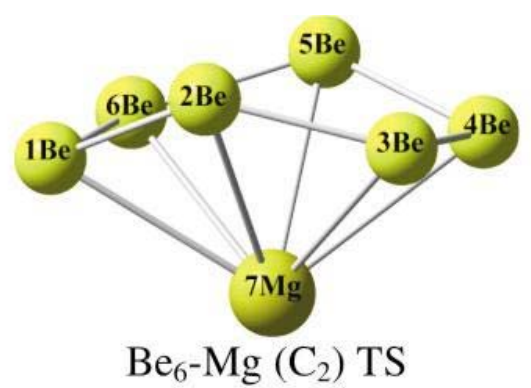

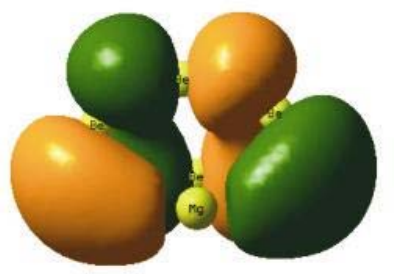

$\mathrm{Be}_{6}-\mathrm{Mg}$ (TS) HOMO

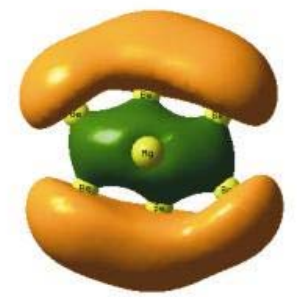

$\mathrm{Be}_{6}-\mathrm{Mg}(\mathrm{TS}) \mathrm{LUMO}$
Figure 8. Optimized structures (B3LYP/6-311+ $\mathrm{G}^{*}$ ) and some important frontier molecular orbital pictures of the transition state separating the $\mathrm{Be}_{6}-\mathrm{Mg}$ (I) and $\mathrm{Be}_{6}-\mathrm{Mg}$ (II) isomers (scheme 4).

Finally, we analyse the bonding, reactivity and aromaticity patterns in $\mathrm{Mg}$-doped Be-clusters (scheme $\mathrm{S} 4)$. In table $\mathrm{S} 14$ we present two 'bond- stretch' isomers ${ }^{21,22}$ of $\mathrm{Be}_{6}-\mathrm{Mg}$. The $\mathrm{Be}_{6}-\mathrm{Mg}\left(\mathrm{C}_{6 v}\right)$ isomers are of almost same energy (variation in the 5 th place of the decimal) and both of them belong to minima (number of imaginary frequency, NIMAG $=0$ ) on the potential energy surface separated by a $\mathrm{C}_{2}$ symmetric transition state $(\mathrm{TS}, \mathrm{NIMAG}=1)$. Associated HOMO and LUMO of these species are presented in figures 7 and 8 . Although the two isomers are of same symmetry, almost same energy and identical frontier orbitals (figure 7), reactivity and aromaticity patterns (table S15), some of the bond lengths of these isomers are different. In case it is a real example of bond-stretch isomerism ${ }^{21,22}$ it will prompt experimentalists to synthesize those isomers.

\section{Concluding remarks}

An abrupt change in the bonding and reactivity patterns is noticed when the $\mathrm{Cp}^{-}$ring in $\mathrm{Cp}-\mathrm{Fe}-\mathrm{Cp}$ is substituted by the incoming superatoms. The $\mathrm{Al}_{4}^{2-}$ moiety is unable to maintain its planarity. The $\mathrm{B}_{3}^{-}$ and $\mathrm{B}_{4}^{2-}$ ligands on bonding with the $\mathrm{Fe}$ atom cannot preserve the expected sandwiched structure and form flanked clusters. The spontaneity of the pro- posed reactions are somewhat justified from their $\Delta H$ and $\Delta \omega$ values. Associated noticeable changes in aromaticity of the attacking moieties are also observed. Site selectivity of different atomic centers towards electrophilic and nucleophilic attacks is understood. Bond-stretch isomerism is noticed in the $\mathrm{Be}_{6}-\mathrm{Mg}$ cluster.

\section{Acknowledgements}

The financial assistance from Council of Scientific and Industrial Research (CSIR), New Delhi is gratefully acknowledged.

\section{Supporting information}

Optimized geometrical parameters like bond length (in $\AA$ ) and bond angles (in degrees) for all the molecules involved in schemes $\mathrm{S} 1-\mathrm{S} 4$ and tables $\mathrm{S} 1-\mathrm{S} 15$ are also given in supplementary information (see www.ias.ac.in/chemsci).

\section{References}

1. Kekulé A 1865 Bull. Soc. Chim. Fr. (Paris) 398

2. (a) Minkin V I, Glukhovtsev M N and Simkin B Y 1994 Aromaticity and antiaromaticity: Electronic and structural aspects (New York: John Wiley \& Sons); (b) Schleyer P v R (Guest editor) 2001 Chem. Rev. 101 (special issue on Aromaticity); (c) Aromaticity and Metal Clusters (ed.) P K Chattaraj 2009 (Florida: Taylor \& Francis/CRC Press (to appear))

3. Phukan A K, Kalagi R P, Gadre S R and Jemmis E D 2004 Inorg. Chem. 435824

4. Li X, Kuznetsov A E, Zhang H F, Boldyrev A I and Wang L S 2001 Science 291859

5. (a) Li X, Zhang H F, Wang L S, Kuznetsov A E, Cannon A N and Boldyrev A I 2001 Angew. Chem. Int. Ed. 40 1867; (b) Chattaraj P K, Roy D R, Elango M, Subramanian V 2006 J. Mol. Struc. (Theochem.) 759 109; (c) Kuznetsov A E, Boldyrev A I, Li X and Wang L S $2001 \mathrm{~J}$. Am. Chem. Soc. 123 8825; (d) Boldyrev A I and Wang L S 2005 Chem. Rev. 105 3716 and references therein; (e) Tsipis C $2005 \mathrm{Co}$ ord. Chem. Rev. 249 2740; (f) Chattaraj P K and Roy D R 2007 J. Phys. Chem. A111 4684; (g) Chattaraj P K, Sarkar U and Roy D R 2007 J. Chem. Edu. 84 354; (h) Mallajosyula S S, Datta A and Pati S K 2006 J. Phys. Chem. B110 20098; (i) Datta A, Mallajosyula S S and Pati S K 2007 Acc. Chem. Res. 40213

6. (a) Mercero J M and Ugalde J M $2004 \mathrm{~J}$. Am. Chem. Soc. 126 3380; (b) Fang L, Yang G C, Qiu Y Q and Su Z M 2008 Theo. Chem. Acc. 119329

7. (a) Li Q S and Cheng L P 2003 J. Phys. Chem. A107 2882; (b) Li Z, Zhao C and Chen L $2007 \mathrm{~J}$. Mol. Struc. (Theochem.) 8101 
8. (a) Parr R G and Yang W 1989 Density functional theory of atoms and molecules (New York: Oxford University Press); (b) Chattaraj P K and Giri S 2009 Annu. Rep. Prog. Chem. Sect. C: Phys. Chem. 105 13; (c) Chattaraj P K (ed.) 2009 Chemical Reactivity Theory: A Density Functional View (Florida: Taylor \& Francis/CRC Press)

9. (a) Sen K D and Jorgenson C K 1987 Structure and bonding, electronegativity (eds Berlin: Springer) vol 66; (b) Parr R G, Donnelly R A, Levy M and Palke W E 1987 J. Chem. Phys. 683801

10. (a) Sen K D and Mingos D M P 1993 Structure and bonding: chemical hardness (eds Berlin: Springer) vol 80; (b) Parr R G and Pearson R G $1983 \mathrm{~J}$. Am. Chem. Soc. 105 7512; (c) Pearson R G 1997 Chemical hardness: applications from molecules to solids (Weinheim: Wiley-VCH)

11. (a) Parr R G, Szentpaly L v and Liu S $1999 \mathrm{~J}$. Am. Chem. Soc. 121 1922; (b) Chattaraj P K, Sarkar U and Roy D R 2006 Chem. Rev. 106 2065; (c) Chattaraj P K and Roy D R 2007 Chem. Rev. 107 PR46

12. Mulliken R S 1955 J. Chem. Phys. 231833

13. Parr R G and Yang W 1984 J. Am. Chem. Soc. 106 4049

14. Schleyer P v R, Maerker C, Dransfeld A, Jiao H and Hommes R v E N J 1996 J. Am. Chem. Soc. 1186317
15. (a) Chattaraj $\mathrm{P} \mathrm{K}$, Pérez $\mathrm{P}$, Zevallos $\mathrm{J}$ and ToroLabbé A 2001 J. Phys. Chem. A105 4272; (b) Chamorro E, Chattaraj P K and Fuentealba P $2003 \mathrm{~J}$. Phys. Chem. A107 7068; (c) Parthasarathi R, Elango M, Subramanian V and Chattaraj P K 2005 Theor. Chem. Acc. 113 257; (d) Chattaraj P K, Roy D R and Giri S 2007 Comp. Lett. 3 223; (e) Noorizadeh S 2007 J. Phys. Org. Chem. 20 514; (f) Chattaraj P K and Giri S 2007 Indian J. Phys. 81 871; Chattaraj P K and Giri S 2008 Indian J. Phys. 82 467; (g) Noorizadeh S and Shakerzadeh E $2008 \mathrm{~J}$. Mol. Struc. (Theochem.) 86822

16. Yang W and Mortier W J $1986 \mathrm{~J}$. Am. Chem. Soc. 1085708

17. Chattaraj P K, Maiti B and Sarkar U 2003 J. Phys. Chem. A107 4973

18. Gaussian 03, Revision B.03; Gaussian, Inc.: Pittsburgh, PA, 2003

19. Zhi-R U L, Fang-Fang W, Di W, Ying L, Wei C, Xiao-Ying S, Feng L G and Yuriko A $2006 \mathrm{~J}$. Comput. Chem. 27986

20. Li Z, Zhao C and Chen L 2007 J. Mol. Struc. (Theochem.) 8101

21. Parkin G 1992 Acc. Chem. Res. 25455

22. Rohmer M-M and M Bénard 2001 Chem. Soc. Rev. 30340 